\title{
DISCUSSION ON THE RELAXATION CAMP FACILITY MANAGEMENT AND THE ESTABLISHMENT OF THE INFORMATION SYSTEM
}

\author{
$\underline{\text { Yan-Chyuan Shiau }}^{1}{ }^{*}$, Lian-Ting Lu², Meng-Jia Yeh², Shu-Jen Song ${ }^{2}$, and Chin-Ting Wang ${ }^{3}$ \\ ${ }^{1}$ Department of Construction Management, Chung Hua University, Hsin-Chu, Taiwan \\ ${ }^{2}$ College of Management, Chung Hua University, Hsin-Chu, Taiwan \\ ${ }^{3}$ Master Degree, Department of Construction Management, Chung Hua University, Hsin-Chu, Taiwan \\ *Corresponding author (ycshiau@ms22.hinet.net)
}

\begin{abstract}
Information management became the tidal for most occupations. An effective management system to integrate related information for relaxation camp can provide effectiveness from different phases. This can enhance the farm value, feedback with ecology care, and significantly assist for long-term development. In "Medium-range Construction Plan for Important Sightseeing Scenic Spot", the Ministry of Communications Sightseeing Bureau in Taiwan indicated government only emphasizes on hardware demand and neglects the management and operation need. The major sightseeing scenic spots are lack support of management software. An integrated management system can significantly help the promotion of the sightseeing industry. In this study, ER Model, database, SQL Server, Visual Studio, and Windows environment are used to develop "Relaxation Camp Facility Management System". The system integrates related information such as recreation facility, business model, livestock product, experience item, and service space. The related information of relaxation camp is combined in the system that provides tourist to inquire from the website for assistance. This makes the leisure industry concerns agriculture content, marketing and management domain. Besides building pleasant environment, the system can create extra values for farms. Through the help of this system, farm personnel can engage in the farm plan design, provides appropriate related information, and propose the right direction for relaxation camp development.
\end{abstract}

Keywords: Relaxation Camp, Facility Management, Database, ER Model

\section{INTRODUCTION}

\subsection{Research Background}

Leisure farms are actively targeted by the government for coaching to encourage more farmers and related industries to participate in the management of leisure farms [1]. In a research by Wang Chin-Tsan on the management models of leisure farms, he proposed key points which must be emphasized during different stages of development, such as internal/external environment resource analysis, core strategy formulation, customer relationship/value network strengthening and strategic investment in creativity [2]. In particular, in terms of computer information services, the majority of the farmers are less adequate; meanwhile, the Tourism Bureau of MOTC pointed out in the Major Scenic Spot Development Midterm Project problem analysis that in the past, tourism development was often focused on hardware requirements and neglected the needs for follow-up management and operations. Meanwhile, important scenic spots also lack the support of operations and management software [3].

Due to the change in domestic industry structure and the opening of the market after joining the WTO, the agricultural industry has experienced a significant impact; therefore, domestic agricultural industry is also actively transforming towards leisure agriculture. With the improvement in the quality of life in Taiwan, the concept on recreation has also changed, therefore there is increasing number of leisure farms in Taiwan; as result, the operation and management of leisure farms has become extremely important as well.

\subsection{Research Objective}


Through progress in technology, the digitization of various industries is a certain trend. The objective of this research is to probe into the application of information on leisure farms and the development of management systems. The research objectives are:

A. Compile the current status of leisure farm management, the services provided and the required spaces/facilities, etc., through literature review. Moreover, the analysis on system functionalities will be conducted.

B. Using the ER Model and database to create a Leisure Farm Facility Management System, which includes various data forms, columns, attributes and relationships.

C. Utilize the windows environmental tool to develop the Leisure Farm Facility Management System and enter the domestic leisure farm information in order to verify the system function.

\section{LEISURE FARMS IN TAIWAN}

\subsection{Current Leisure Farm Conditions in Taiwan}

After the implementation of a policy of two days offs per week, the quality of life for the people of Taiwan has improved, and the frequency of tourism activities after work has also increased. After joining the WTO, the agricultural industry suffered significant impact and numerous farms were transformed into leisure farms as a result. According to statistics by the COA, there are currently 1,102 leisure farms in the industry.

Most of the leisure farms are distributed in the north (44.7\%); this is because the demand for leisure farms is greater in the north (as shown in Table 1). When examined from an administrative unit perspective, Yilan County topped the ranking with 128 farms while Nantou County came second with 100 farms; leisure farms in both counties combine to form one-fifth of the national figure. They are followed by Taoyuan County, Taipei City, Taichung County and Miaoli County; the six above mentioned cities and counties combine to form over half of the number of leisure farms in Taiwan. On average, there are three leisure farms for every town/township/city.

By moving from agriculture to leisure agriculture, the nature of farming is no longer simple agricultural work, it al- so includes operations, management and marketing, which are in turn more challenging aspects for farmers. Therefore, alliance organizations have been formed among the farms such as the Taiwan Farmers Management Association and Taiwan Leisure Farms Development Association; these farms are certified for their quality, hoping to increase service quality, promote overall marketing and generate agricultural development. They also act as a communication bridge with the government and farm related regulations.

Table 1. Distribution of leisure farms in Taiwan

\begin{tabular}{|c|c|c|c|c|c|c|c|}
\hline Zone & County & $\begin{array}{l}\text { Amo } \\
\text { unt }\end{array}$ & \begin{tabular}{|l|} 
Per- \\
centage
\end{tabular} & Zone & County & $\begin{array}{l}\text { Amoun } \\
\mathrm{t}\end{array}$ & $\begin{array}{l}\text { Percent- } \\
\text { age }\end{array}$ \\
\hline \multirow{7}{*}{ North } & Yilan & 128 & $11.6 \%$ & \multirow[t]{7}{*}{ South } & Jiayi & 37 & $3.4 \%$ \\
\hline & Keelong & 10 & $0.9 \%$ & & Tainan & 56 & $5.1 \%$ \\
\hline & Taipei & 91 & $8.3 \%$ & & $\begin{array}{l}\text { Kaoshong } \\
\text { City }\end{array}$ & 6 & $0.5 \%$ \\
\hline & \begin{tabular}{|l} 
New \\
Taipei
\end{tabular} & 65 & $5.9 \%$ & & Kaoshong & 38 & $3.4 \%$ \\
\hline & Taoyuan & 94 & $8.5 \%$ & & Pingdong & 33 & $3.0 \%$ \\
\hline & Hsinchu & 34 & $3.1 \%$ & & Ponghu & 9 & $0.8 \%$ \\
\hline & Miaoli & 70 & $6.4 \%$ & & & & \\
\hline \multicolumn{2}{|c|}{ Subtotal } & 492 & $44.7 \%$ & \multicolumn{2}{|c|}{ Subtotal } & 179 & $16.2 \%$ \\
\hline \multirow{5}{*}{$\begin{array}{l}\text { Cen- } \\
\text { tral }\end{array}$} & $\begin{array}{l}\text { Taichung } \\
\text { City }\end{array}$ & 74 & $6.8 \%$ & \multirow[t]{2}{*}{ East } & Hwalian & 50 & $4.5 \%$ \\
\hline & Taichung & 24 & $2.2 \%$ & & Taidong & 60 & $5.4 \%$ \\
\hline & Nantou & 100 & $9.1 \%$ & \multicolumn{2}{|c|}{ Subtotal } & 110 & $9.9 \%$ \\
\hline & Janghua & 62 & $5.6 \%$ & \multirow[t]{2}{*}{ Islands } & \multirow[t]{2}{*}{ Kingmon } & 6 & $0.5 \%$ \\
\hline & Yunlin & 55 & $5.0 \%$ & & & & \\
\hline \multicolumn{2}{|c|}{ Subtotal } & 315 & $28.7 \%$ & \multicolumn{2}{|l|}{ Total } & 1,102 & $100.0 \%$ \\
\hline
\end{tabular}

\subsection{Types of Leisure Farms in Taiwan}

According to the Regulation for Counseling and Governance of Recreation Agriculture as promulgated by the COA, the types of leisure farms in Taiwan are:

A. Simple leisure farm: this refers only to leisure farms with farming experience subzones.

B. Composite leisure farm: this refers to leisure farms with farming experience subzone and tourist recreational subzones.

\section{FARM FACILITIES AND ACTIVITIES}

\subsection{Leisure Farm Facilities}

Leisure farm facilities are the primary element for promoting leisure agriculture and leisure farm planning. According to the current Regulation for Counseling and Governance of Recreation Agriculture, the farming experience subzone may be used for the purposes of experiencing farming management, natural landscapes, ecological preservation and education, while the tourist leisure sub-zone is 
for the purposes of lodging, dining, processing (brewing) the self-produced crops, exhibiting (sale) of farm products and rural cultural crafts, education interpretation center, and facilities relevant to the recreation agriculture.

According to Zhang Hong-wei (2003)'s examination of the facilities required for leisure agriculture from the leisure farm management perspective, four categories may be derived via the viewpoint of the Life, Production and Business environment of agriculture, including: farming management, farming experience, tourist recreation and ordinary services. They are described below [4]:

\section{A. Farming management facilities}

Involved directly in the facilities required for farming production and processing, including cultivated land, cottage, livestock, faming tools and all ancillary facilities on the land.

B. Farming environment experience facilities

By adding the facility into the original farming production equipment, they are able to cater to the tourists' needs for a farming experience. For instance, crop guidance facility, farming assistance facility and props/facilities for event participation, etc.

C. Tourist recreational facilities

Provides facilities needed for the tourists' recreational services. The tourist recreational facility's function is different from that of conventional recreational facilities; tourist recreational facilities on leisure farms should allow visitors to feel experiences such as farming management, farming village life and an ecological environment, so as to allow their minds and behaviors to be infused into the farm village living scenario.

D. Farming service and other facilities

Provides facilities required for the movement path, environmental cleaning, transportation system (such as farm road, parking lot, toilet facilities) and ventilation system (drinking water, telecommunications, air, noise and sunshine) on the leisure farm.

\subsection{Leisure Farm Activities}

When transforming from farming management activity into composite agricultural and conventional recreational activities, a leisure farm must consolidate its existing agri- cultural resource characteristics in order to generate visitor knowledge on farming production, life and ecology. Based on their nature, four basic constructs may be formed [5]:

A. Farming environment and farm village experience activity

B. Agriculture and natural ecology education / interpretation activity

C. Outdoor recreation and sightseeing activity

D. Festivity and research/study activity

Wang Wei-Che (1997) proposed two types of recreational experiences provided by leisure farms [6]:

A. Farming environment experience

Farming environment experience includes getting to know the crop cultivation proof and production process, farmer's work and the process of farming, understanding the breeding and production process of livestock, food production process and method, experiencing a farm village's tranquility and leisurely lifestyle, coming into contact with farmers in order to appreciate their way of life, as well as to experience the rich cultural characteristics of farm villages.

B. Conventional recreational experience

Conventional recreational experience includes admiring natural landscapes, being with family to enhance relationships and feelings, getting away from the hubbub of the world, obtaining opportunities for spiritual relaxation, becoming better acquainted with friends, strengthening fitness and body health, experiencing the excitement of wilderness and adventurous environments, enjoying convenient and comfortable dining / accommodation services.

\section{LEISURE FARM FACILITY MANAGEMENT IN- FORMATION SYSTEM}

\subsection{System Functionality Analysis}

The study's functionality analysis of the leisure farm facility management system divides the system into three major items such as basic information operation, joint information operation and searching operation. The three categories each features different maintenance sub-items (as shown in Fig. 1).

(1) Basic Data Operation 

A. Agricultural Product Maintenance
B. Livestock Product Maintenance
C. Management Model Maintenance
D. Experience Type Maintenance
E. Service Space Maintenance
F. Surrounding Environment Maintenance
G. Related Facilities Maintenance
H. Used Unit Maintenance
(2) Farm Data Operation
A.Farm Basic Data
B.Farm Experience Items
C.Farm Service Space
D.Farm Surrounding Scenic Spots
E. Farm Related Facilities
F. Farm Agricultural Product
G.Farm Livestock Product

(3) Data Search Operation
A. Keyword Search
B. Regional Data Search
C. Environmental Data Search
D. Scale Data Search

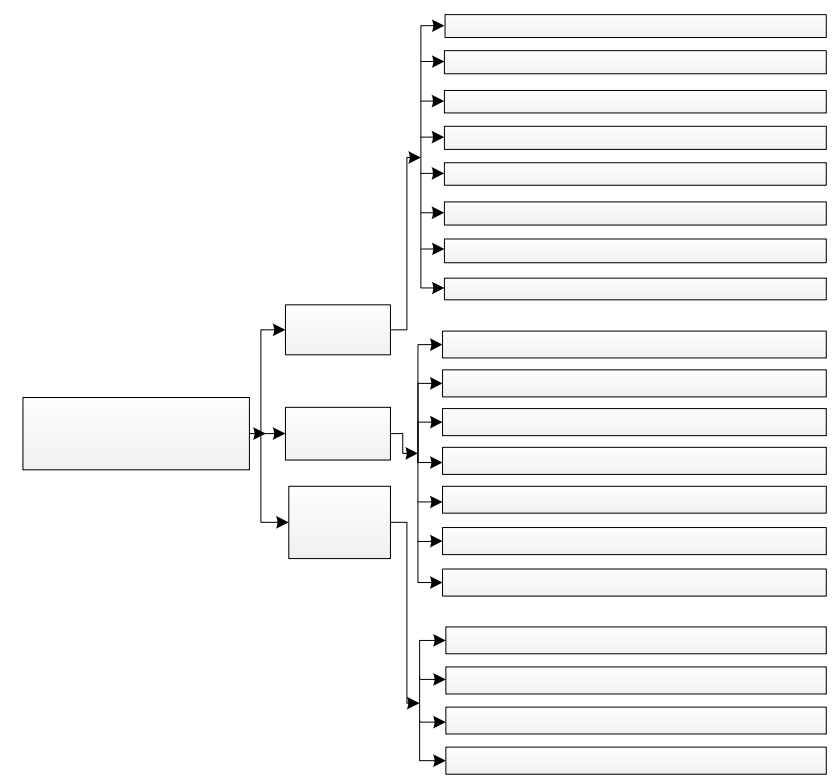

Fig. 1 System framework

\subsection{System database structure}

The study's ER/Model is created using ER/Studio, the system is capable of transforming logic module into physical module (as shown in Fig. 2) before exporting the data into SQL Server via ODBC. The database adopts standardized procedures to ensure efficiency and ease of maintenance; furthermore, instances such as data repetition or contradiction may be avoided.

\section{SYSTEM OPERATION AND VERIFICATION}

The section will introduce the various functional modules in the Leisure Farm Facility Management System. The study enters the collected data on leisure farms into the database to verify the normal operation of the database management end and webpage end. The system is divided into Basic Data Operation, Farm Data Operation and Data Search Operation:

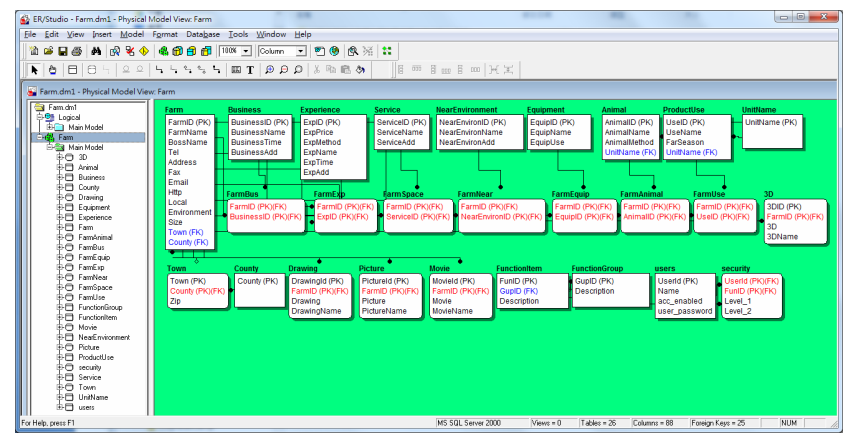

Fig. 2 Physical module of leisure farm management system

\subsection{Basic Data Operation}

Basic data operation is provided to operators for maintenance of the leisure farm's basic data; the basic common data will be set up in different farms and includes eight sub-functions:

A. Agricultural product maintenance: maintains all agricultural product information of the farm, including: agricultural product serial number, name, production season, etc. (as illustrated in Fig. 3).

B. Livestock product maintenance: maintains all livestock product information of the farm, including: livestock product serial number, name, breeding method, organization, etc. (as shown in Fig. 4).

C. Management model maintenance: maintains the farm's management model.

D. Experience item maintenance: maintains the commonly used experience facilities on the farm (as shown in Fig. 5).

E. Service space maintenance: maintains the data for 
commonly used space on the farm.

F. Surrounding scenic spot maintenance: maintains surrounding scenic spots (as shown in Fig. 6).

G. Ancillary facility maintenance: maintains ancillary farm facilities.

H. Usage organization maintenance: maintains other organizations used by other modules.

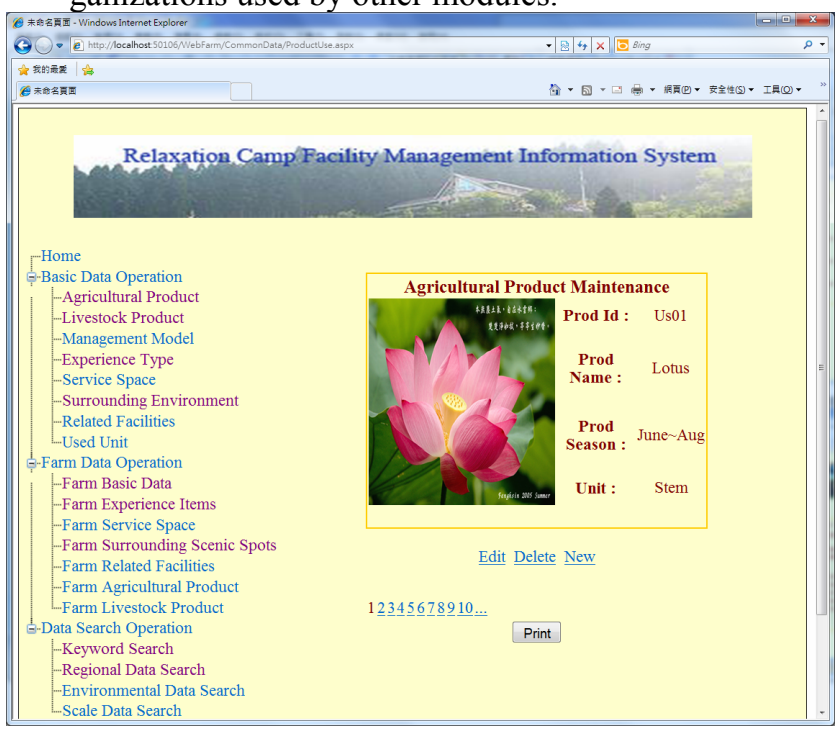

Fig.3 Agricultural product module display

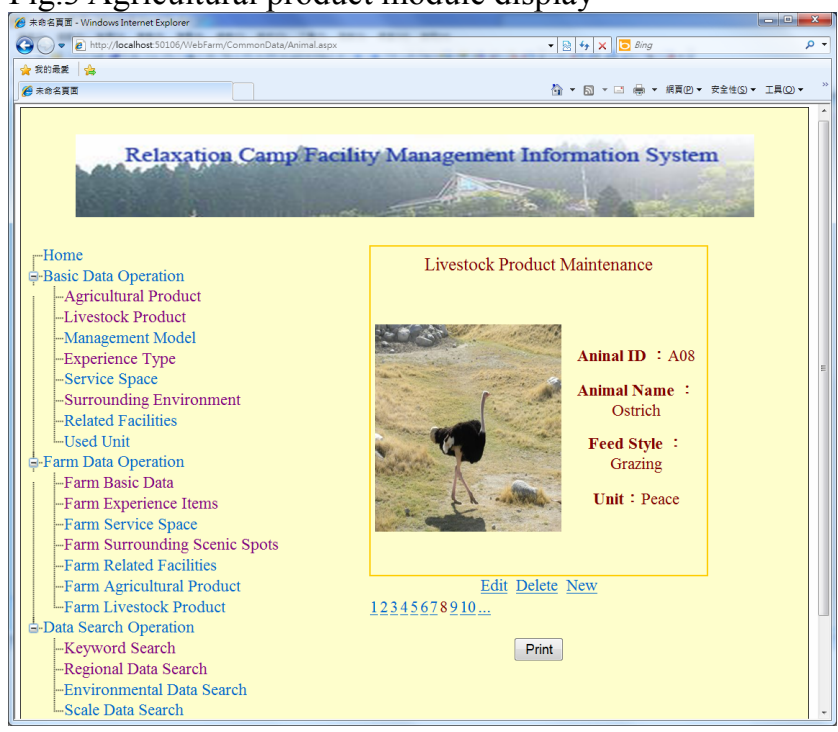

Fig.4 Livestock product utilization module display

\subsection{Farm Data Operation}

Farm data operation provides the manager with maintenance and configuration operations concerning leisure farm related data using data stored in the Basic Data Operation, so that visitors may conduct searches. The seven sub- functions include:

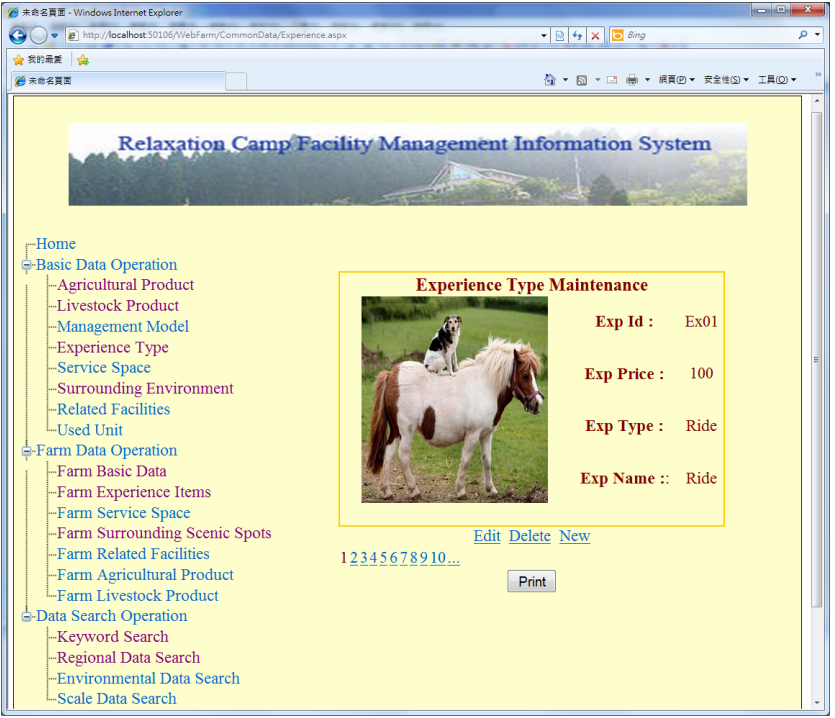

Fig.5 Experience item maintenance module display

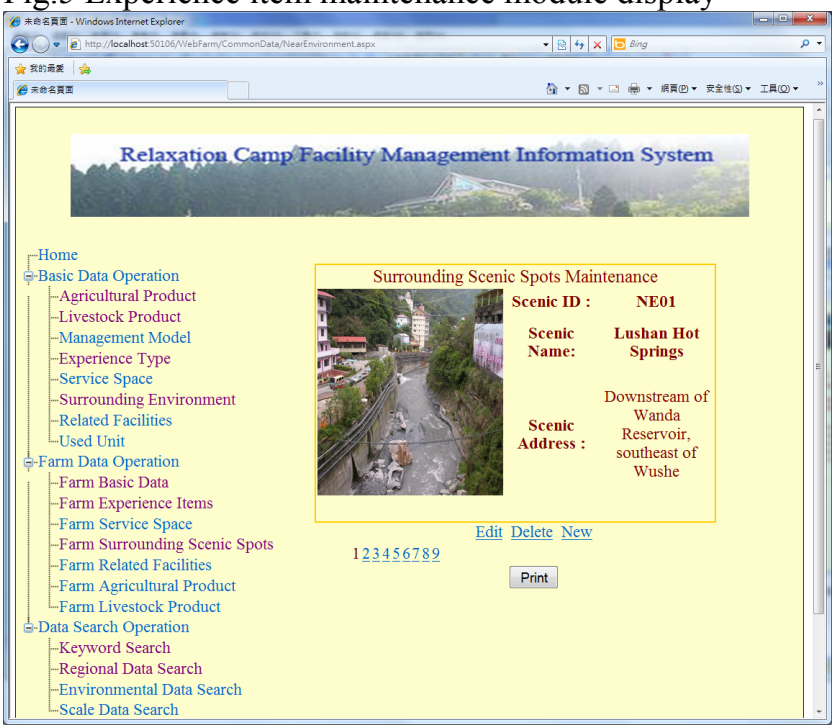

Fig.6 Farm surrounding scenic spot maintenance module display

A. Farm basic data: configure the farm's serial number, name, telephone and address, etc. (as shown in Fig. 7).

B. Farm experience items: configure the farm's information such as experience items, prices and time.

C. Farm service space: configure the farm's service space, including accommodation, restaurant and service center, etc.

D. Farm surrounding scenic spots: configure the farm's surrounding scenic spots and positions and provide to the general public for reference when planning tours.

E. Farm ancillary facilities: configure the farm's ancillary facilities and positions so as to allow people to under- 
stand if they conform to their needs and thereby use them as references for selecting tours.

F. Farm agricultural product utilization: configure the farm's agricultural product information and production season, so that the public may learn when to participate in the harvesting experience of agricultural products and other related activities.

G. Farm livestock product utilization: configure the farm's livestock product categories and breeding methods for the public's reference.

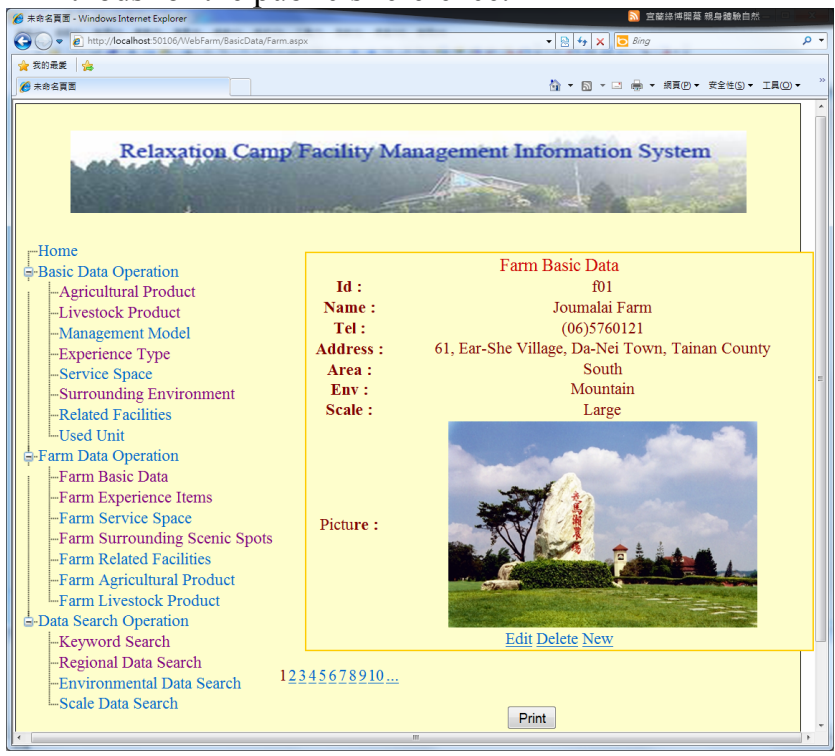

Fig. 7 Farm basic data module display

\subsection{Data Search Operation}

The study focuses on farm data to provide four search methods to facilitate the user in finding the required information easily and quickly:

A. Key word search: after entering the key word, data related to the keyword will be searched.

B. Regional data search: Taiwan is divided into four regions such as the north region, central region, south region and east region.

C. Environmental data search: the farms are divided into mountainous region or level ground categories for searching.

D. Scale data search: the farms are divided according to three categories such as large, medium and small.

\section{CONCLUSION}

The study examines the current conditions, spaces and ancillary facilities of leisure farms through literature review; interviews are conducted by experts to confirm the system's functional structure, including various data forms, column attributes, main index, restrictions and the relationship between columns.

Furthermore, ER Studio is used to establish the database structure, while Visual Studio 2008 and Asp.net were used to develop the Leisure Farm Facility Management Information System. The functions were tested by entering the case example, and user feedback was collected to make revisions to the system's functions. The contributions are as below:

A. Leisure farm operators may establish their farms on the website for consumers to browse in order to increase exposure and sales performance.

B. When planning recreational itineraries, the public may look up the destinations' services, spaces and facilities in order to achieve the objectives of the tour, thereby preventing disappointment after returning home due to the difference between expectation and reality.

C. The user may search for other scenic spots near the farm before departure to plan for the entire trip beforehand, thereby ensuring a quality leisure activity.

\section{REFERENCES}

[1] Chiu, Yung-Chung, Business Science of Leisure Farms, Maochang Books Co., Ltd., Taipei, 2002.

[2] Wang Chin-Tsan, Study on the Management Models of Leisure Farms, Master's dissertation, Department of Construction Management, CHU, 2008.

[3] Tourism Bureau, MOTC, http : //admin.taiwan.net.tw lindexc.asp

[4] COA, Executive Yuan Website, http: //www.coa. gov.tw /show index.php

[5] Chang, Hung-Wei, Study on the Legitimacy of Leisure Farm Facilities, Sino-Japanese International Leisure Farm Symposium Dissertation Collection, P31-48, 2003.

[6] Wang, Wei-Che, The Study on Visitors' Cognition and Experience to the Leisure Agriculture, Master's dissertation, Graduate School of Architecture, FCU, 1997 